Published as: Ögren, M, H. Andersson, T. Jerson, 2015, Noise and Vibration Mitigation for Rail Transportation Systems, in series Notes on Numerical Fluid Mechanics and Multidisciplinary Design, Chapt. "Comparison between Road and Rail Noise Cost per Transported Ton of Cargo”, in Nielsen, J.C.O., et al (eds.), Vol. 126, 2015, pp 79-84.

\title{
Comparison between road and rail noise cost per transported ton of cargo
}

\author{
M. Ögren ${ }^{1}$, H. Andersson ${ }^{2}$ and T. Jerson ${ }^{3}$ \\ ${ }^{1}$ Occupational and Environmental Medicine, \\ Sahlgrenska Academy, Univ. of Gothenburg, Sweden, \\ Tel: +46 31786 3629, E-mail: mikael.ogren@amm.gu.se \\ ${ }^{2}$ Toulouse School of Economics (UT1, CNRS, LERNA), France \\ ${ }^{3}$ WSP Acoustics, Gothenburg, Sweden
}

\begin{abstract}
Summary
The social cost of noise is normally used when performing cost-benefit analysis while planning infrastructure projects or noise mitigation measures. In this study it is used together with the official noise prediction methods to estimate the acoustic and monetary impact of transporting 1 ton of cargo through two separate transportation corridors from Gothenburg to Stockholm in Sweden, one via railway and the other via truck transport. The noise cost per transported ton is approximately twice as high for rail transport due to higher noise emissions per ton and more exposed dwellings close to the railway.
\end{abstract}

\section{Introduction}

The social cost of noise is normally used when performing benefit-cost analysis (BCA) while planning infrastructure projects or noise mitigation measures. There are many national models for determining the yearly cost of being exposed at home to a certain noise level, and they typically assign a valuation that gives the monetary effect as a function of the equivalent noise level in $\mathrm{dB}$ at the exposed façade of the dwelling. In this study we have used the official noise values in use in Sweden for road and railway traffic (ASEK 5) [1] together with the official noise prediction methods [2-3] to estimate the acoustic and monetary impact of transporting 1 ton of cargo through two example transportation corridors. 


\section{Method}

The method employed in this paper is described in detail in [4], but the basic steps are to calculate the noise level at each residence using the standardized Nordic prediction methods for road and railway traffic noise [2-3], and then calculate the marginal increase in noise level one additional train/truck passage causes. The short run marginal cost (SRMC) can then be calculated using the official valuation functions by adding up the contribution for each residence along the road or railway segment under study.

The main difficulty with applying the method in practice is the demand for accurate input data, not only on the location of all residences close to the road or railway line and the total traffic flows including speeds, but also on all potentially screening objects such as terrain, buildings, noise barriers and so on. In this study we have chosen to simplify the input data as described in Table 1. The data on the infrastructure was supplied by the Swedish Traffic Administration (Trafikverket) and the Swedish National Road Database (NVDB). The population data was supplied by Statistics Sweden (SCB).

Table 1. Input data with data source and approximate resolution

\begin{tabular}{|c|c|}
\hline Input data & Source and resolution \\
\hline Railway network & Trafikverket, GIS lines including traffic per 24h, \\
25 m resolution
\end{tabular}

For each population square (with $250 \mathrm{~m}$ side) the population was assumed to be uniformly distributed over the whole area of the square, except that no population was assumed closer to the source than $25 \mathrm{~m}$. No detailed data on ground attenuation, noise barriers and screening by terrain was available so instead a simplified method was used where the inhabitants in each square were assumed to be distributed over both directly exposed positions and other screened positions. The distribution function was modeled after detailed calculations in more than 1,200 receiver positions in five different railway exposed areas and three road traffic noise exposed areas in Sweden [5]. The accuracy of the simplification is hard to estimate, but a crude estimation using two reference areas not used for the fitting of the model with approximately 100 receivers gives an uncertainty of $\pm 35 \%$ on the calculated SRMC.

The reference train was assumed to be a $500 \mathrm{~m}$ long electrically powered train set with 25 wagons and a total load of 1,500 metric tons. The reference truck was assumed to be a diesel powered vehicle with a total load of 42 metric tons. Both 
were assumed to travel at $90 \mathrm{~km} / \mathrm{h}$ where possible, and at the maximum allowable speed if it was lower than $90 \mathrm{~km} / \mathrm{h}$.

The valuation functions from ASEK 5 [1] give the yearly cost in SEK (1 SEK is approximately 0.15 USD or 0.12 EUR, June 2013) per person exposed as a function of the equivalent $24 \mathrm{~h}$ noise level on the façade of the dwelling. The valuation functions for road and railway traffic noise are shown in Fig. 1. For lower equivalent levels the rail function gives lower values, but the relation is reversed above $69 \mathrm{~dB}$. Note that normally many more inhabitants are exposed to lower levels since the higher levels only can be found very close to the road or railway.

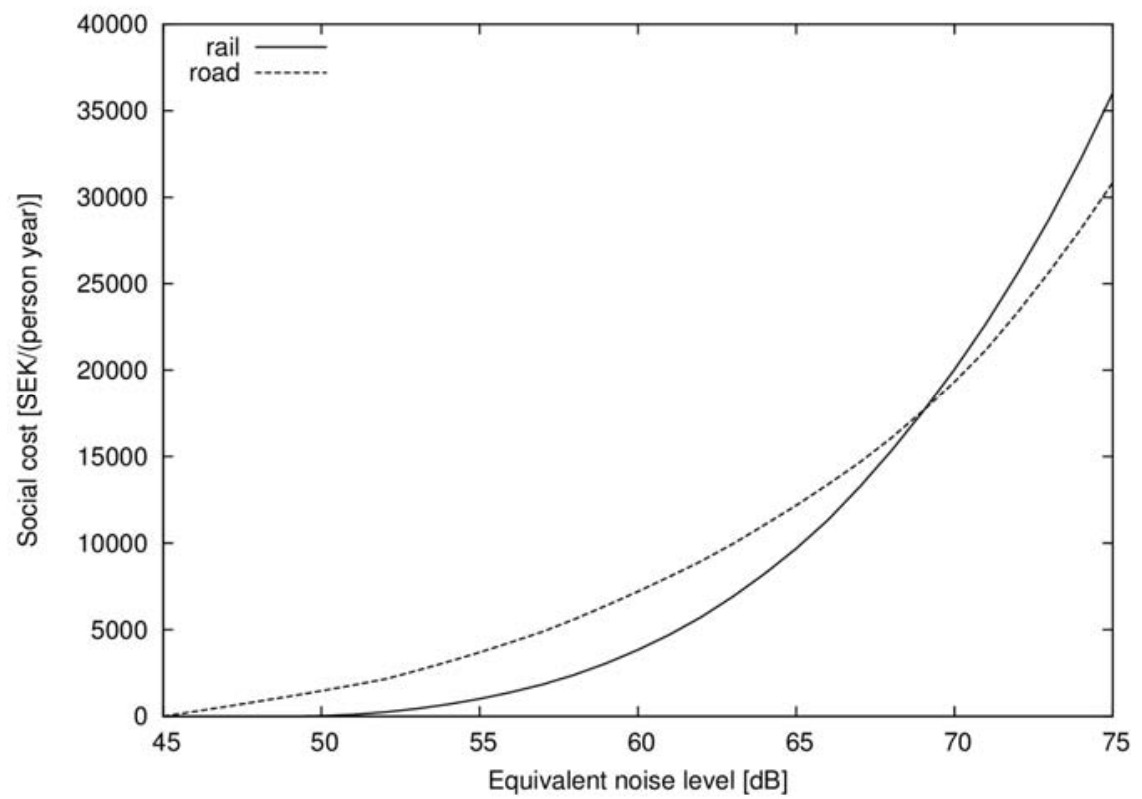

Fig. 1. Official Swedish valuation functions for traffic noise (from ASEK 5 [1]) 


\section{Results}

The calculated SRMC in SEK (price level 2010) is illustrated for each km between Gothenburg and Stockholm in the map in Fig. 2. The area of each circle is proportional to the SRMC or transporting 1 ton of cargo for a $1 \mathrm{~km}$ section of the road or railway. The total distance is $3 \%$ longer for the road than for the railway, see Table 2 . Note that the SRMC is close to zero in rural areas, and it increases sharply where the population density is higher. For areas where no inhabitants live closer to the source than $1 \mathrm{~km}$ the SRMC is identical to zero.

The results are also given in Table 2 and Fig. 3 . The average marginal cost is determined where the cost is high, i.e. more densely populated areas, which gives a skewed distribution where a big part of the road/railway network gives almost no contribution. The number of inhabitants within $1 \mathrm{~km}$ of the source is about equal for both corridors, but note that more inhabitants live closer to the railway. This is probably due to the central location of the railway in many of the urban areas it is passing through, which is in contrast to the road which often circles around the urban centers.

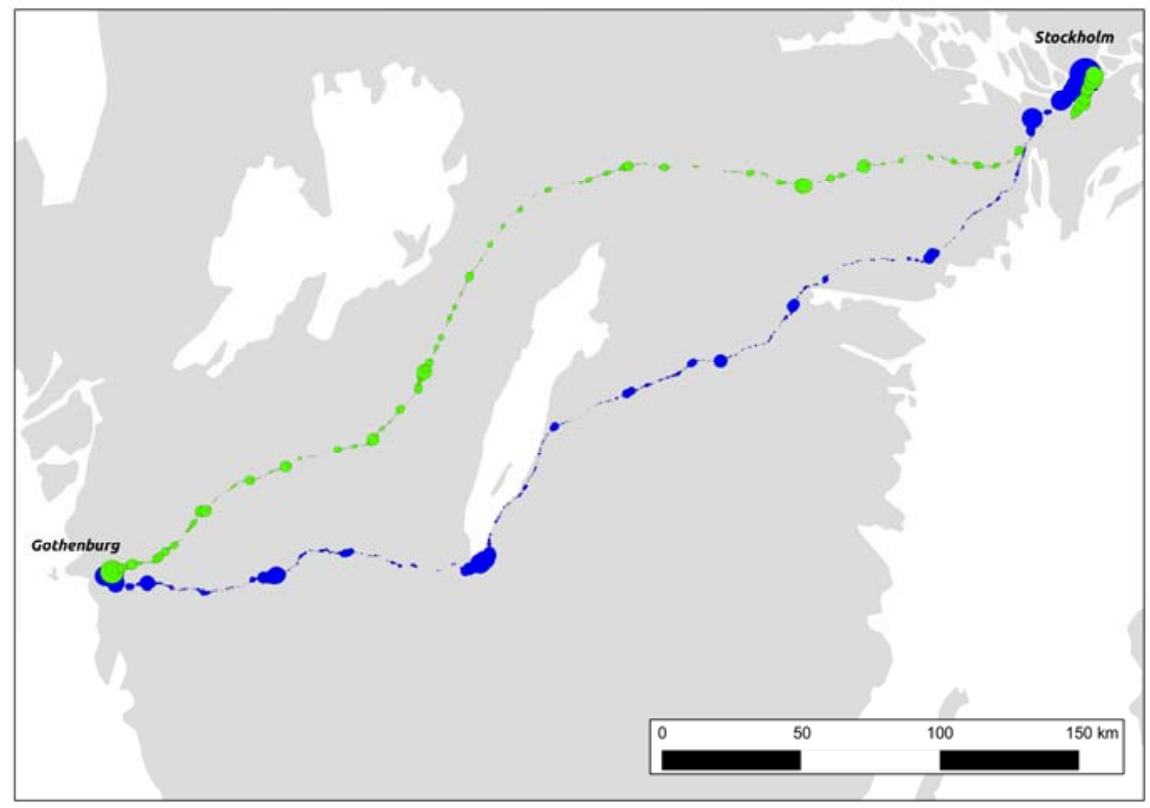

Fig. 2. Map of the marginal cost of transporting 1 ton of cargo between Gothenburg and Stockholm on railway (upper line, light gray) or truck (lower line, dark gray). The area of the circle is proportional to the SRMC. 
Table 2. Description of the transport corridors and calculated SRMC

\begin{tabular}{|c|c|c|}
\hline Parameter & Truck (road) & Freight train (railway) \\
\hline $\begin{array}{l}\text { Length } \\
{[\mathrm{km}]}\end{array}$ & 471 & 458 \\
\hline $\begin{array}{c}\text { Average traffic } \\
24 \mathrm{~h}\end{array}$ & 27500 & 122 \\
\hline $\begin{array}{l}\text { Population } \\
\text { within } 1 \mathrm{~km}\end{array}$ & 409000 & 400000 \\
\hline $\begin{array}{c}\text { Population } \\
\text { within } 250 \mathrm{~m}\end{array}$ & 61000 & 88000 \\
\hline $\begin{array}{l}\text { Noise emission } \\
\text { SEL at } 25 \mathrm{~m} \\
\text { and } 90 \mathrm{~km} / \mathrm{h} \\
{[\mathrm{dB} / \mathrm{ton}]}\end{array}$ & 71.9 & 75.1 \\
\hline $\begin{array}{c}\text { SRMC } \\
1 \text { vehicle } \\
{[\mathrm{SEK} / \mathrm{km}]} \\
\end{array}$ & 0.13 & 10 \\
\hline $\begin{array}{c}\text { SRMC } \\
1 \text { ton } \\
{[\text { SEK/tonkm] }}\end{array}$ & 0.0031 & 0.0069 \\
\hline $\begin{array}{c}\text { SRMC } 1 \text { ton } \\
\text { median (max) } \\
{[\mathrm{SEK} / \text { tonkm] }}\end{array}$ & $0.0002 \quad(0.08)$ & $0.0005 \quad(0.20)$ \\
\hline $\begin{array}{l}\text { SRMC low } \\
\text { noise } 1 \text { ton } \\
\text { [SEK/tonkm] }\end{array}$ & 0.00098 & 0.00069 \\
\hline
\end{tabular}

The last line in Table 2 gives the result for a new calculation assuming a low noise variant of the vehicles. The freight train is assumed to be retrofitted with composite brake blocks (K-blocks) for an overall improvement of $10 \mathrm{~dB}$, see [6]. The truck is assumed to be equipped with low noise mufflers and tires, giving an improvement of $5 \mathrm{~dB}$ according to [7]. For these low noise variants the railway transport has less marginal cost than road transport, showing the important potential for improvement of noise emission of freight wagons. 

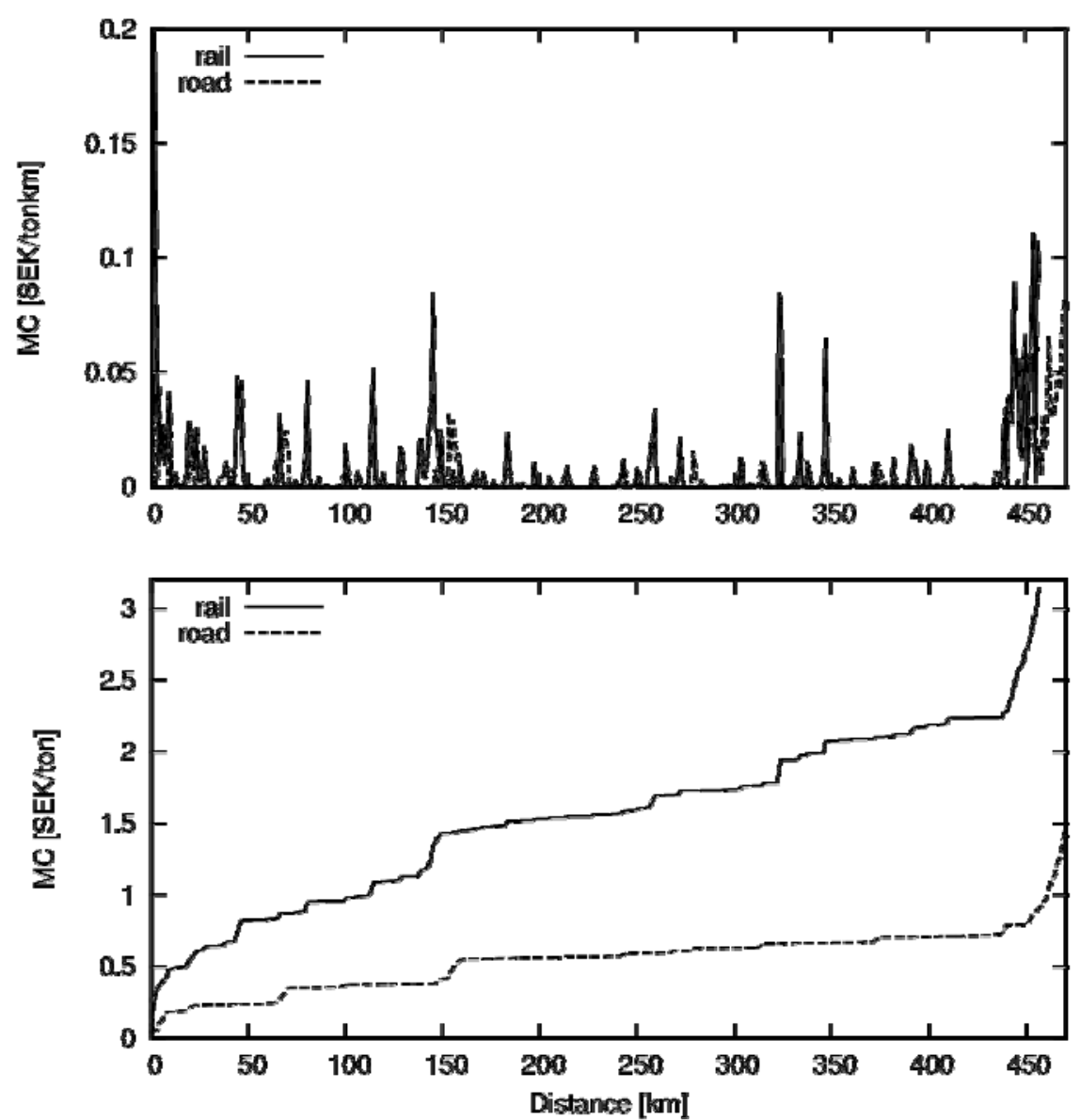

Fig. 3. SRMC for transporting 1 ton of cargo between Gothenburg and Stockholm. Upper picture is cost in SEK/tonkm, lower is accumulated cost in SEK/ton when starting from Gothenburg. 


\section{Discussion}

The average marginal cost is approximately twice as high for rail transport of 1 ton of cargo. This is perhaps surprising considering that the valuation function gives a lower value for railway noise, but it turns out that the higher noise emission per transported ton together with the higher number of inhabitants close to the railway as compared to the road more than compensates for the lower valuation. The potential for reduction is demonstrated by the fact that railway transport gives lower marginal costs per ton if K-blocks are used. If a railway noise charge scheme is implemented where brake type is taken into account it would be a strong incentive for freight vehicle operators to retrofit their train sets using low noise technology. The same is of course true for truck transport.

\section{Acknowledgements}

This project was financially supported by Trafikverket (the Swedish Transport Administration). The authors gratefully acknowledge the support with data from the GIS department of Trafikverket.

\section{References}

[1] Norlin, E. Grudemo, S. et al.: Samhällsekonomiska principer och kalkylvärden för transportsektorn: ASEK 5, (Swedish Transport Administration, 2012).

[2] Ringheim, M. et al.: Railway Traffic Noise - Nordic Prediction Method. TemaNord 1996:524, Nordic Council of Ministers, Copenhagen, Denmark. ISBN 92-9120-837-X.

[3] Jonasson H., Kragh J., et al.: Road traffic noise - Nordic Prediction method. TemaNord 1996:525, Nordic Council of Ministers, Copenhagen, Denmark. ISBN 92-9120-836-1.

[4] Andersson, H. and Ögren, M.: Charging the Polluters, A Pricing Model for Road and Railway Noise. Journal of Transport Economics and Policy 47 (2), 2013.

[5] Ögren, $M$ and Jerson, T.: Mätning och beräkning av buller och vibrationer från tågtrafik inom TVANE-projektet.

[6] Oertli, J. and Hübner, P.: Railway noise in Europe - a 2010 report on the state of the art, International Union of Railways (UIC) 2010.

[7] Sandberg, U. and Ejsmont, J.: Tyre/road noise reference book. Informex 2002. ISBN 91-631-2610-9 